\title{
Final Report (OO-ERD-056) Medios: Modeling Earth Deformation Using Interferometric Observations from Space
}

P. Vincent, B. Walter, J. Zucca, S. Larsen, P. Goldstein, W. Foxwall, F. Ruerson

January 29, 2002

U.S. Department of Energy

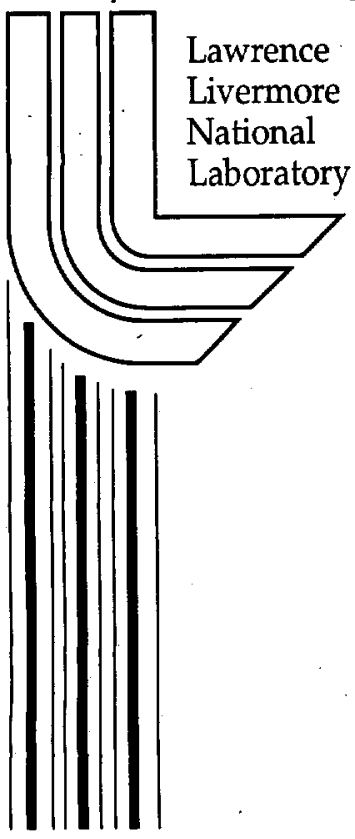




\section{DISCLAIMER}

This document was prepared as an account of work sponsored by an agency of the United States Government. Neither the United States Government nor the University of California nor any of their employees, makes any warranty, express or implied, or assumes any legal liability or responsibility for the accuracy, completeness, or usefulness of any information, apparatus, product, or process disclosed, or represents that its use would not infringe privately owned rights. Reference herein to any specific commercial product, process, or service by trade name, trademark, manufacturer, or otherwise, does not necessarily constitute or imply its endorsement, recommendation, or favoring by the United States Government or the University of California. The views and opinions of authors expressed herein do not necessarily state or reflect those of the United States Government or the University of California, and shall not be used for advertising or product endorsement purposes.

This work was performed under the auspices of the U.S. Department of Energy by the University of California, Lawrence Livermore National Laboratory under Contract No. W-7405-Eng-48.

This report has been reproduced directly from the best available copy.

Available electronically at http://www.doe.gov/bridge

Available for a processing fee to U.S. Department of Energy

and its contractors in paper from

U.S. Department of Energy

Office of Scientific and Technical Information

P.O. Box 62

Oak Ridge, TN 37831-0062

Telephone: (865) 576-8401

Facsimile: (865) 576-5728

E-mail: reports@adonis.osti.gov

Available for the sale to the public from

U.S. Department of Commerce

National Technical Information Service

5285 Port Royal Road

Springfield, VA 22161

Telephone: (800) 553-6847

Facsimile: (703) 605-6900

E-mail: orders@ntis.fedworld.gov

Online ordering: http://www.ntis.gov/ordering.htm

OR

Lawrence Livermore National Laboratory

Technical Information Department's Digital Library

http://www.llnl.gov/tid/Library.html 


\section{Introduction}

This final report summarizes the accomplishments of the 2-year LDRD-ER project "MEDIOS: Modeling Earth Deformation using Interferometric Observations from Space" (00-ERD-056) which began in FY00 and ended in FY01. The structure of this report consists of this summary part plus two separate journal papers, each having their own UCRL number, which document in more detail the major results in two (of three) major categories of this study. The two categories and their corresponding paper titles are 1) Seismic Hazard Mitigation ("Aseismic Creep Events along the Southern San Andreas Fault System"), and 2) Ground-based Nuclear Explosion Monitoring, or GNEM ("New Signatures of Underground Nuclear Tests Revealed by Satellite Radar Interferometry"). The third category is Energy Exploitation Applications and does not have a separate journal article associated with it but is described briefly below.

\section{Purpose and Relevance of Project}

The purpose of this project was to develop a capability within the Geophysics and Global Security Division to process and analyze InSAR data for the purposes of constructing more accurate ground deformation source models relevant to Hazards, Energy, and NAI applications. Once this was accomplished, an inversion tool was to be created that could be applied to many different types (sources) of surface deformation so that accurate source parameters could be determined for a variety of subsurface processes of interest to customers of the GGS Division. This new capability was desired to help attract new project funding for the division.

\section{InSAR Method}

Interferometric synthetic aperture radar (InSAR) has become the standard geodetic tool for mapping surface displacements from a variety of sources such as faults, glaciers, fluid reservoirs (oil, gas, geothermal, volcanic) as well as from soil compaction from aquifer discharge and recharge. The quasicontinuous maps of surface displacement provide the added constraints needed to produce more accurate models of these sources.

Figure 1 shows the basic scanning geometry of a space-borne SAR where a radar backscatter map is formed by scanning the Earth's surface in a side-looking fashion. As the satellite sensor moves along its orbital path with velocity Vs, it transmits microwave pulses and echoes are received from each pulse at the same antenna. The region on the ground illuminated by a single pulse is referred to as the antenna footprint and the entire imaged strip is called the swath. SAR data are divided into $100 \mathrm{~km}$ by $100 \mathrm{~km}$ frames and are processed one-at-a-time. Once processed, individual frames can be combined interfero-

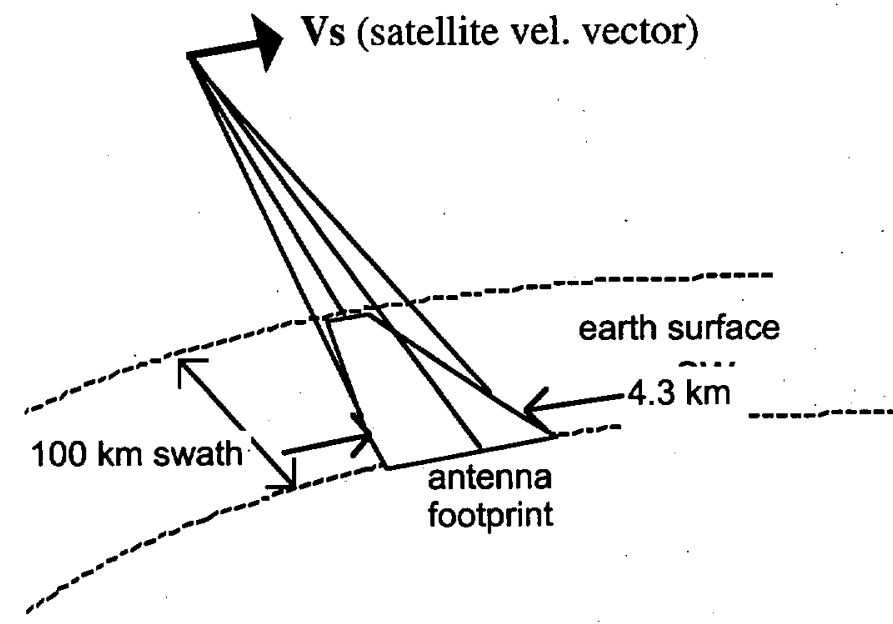

Figure 1. Imaging geometry of a space-borne SAR (swath width and antenna footprint are given for the commercial ERS-1 SAR satellite; Not-to-scale). 
metrically with those from another (repeat) orbit and the resulting phase difference will be proportional to the change in range to the satellite from each ground pixel $(25 \mathrm{~m} \times 25 \mathrm{~m})$ that occurred between imaging times (after topographic phase is removed). From this information, a georeferenced surface deformation map can be produced with sub-centimeter sensitivity and 30 meter resolution. It is these deformation maps, or interferograms, that allow for the construction of more accurate source models by constraining the surface deformation these models are allowed to predict.

\section{Forward Modeling-Analytic (Elastic) Modeling}

Before an accurate tool can be developed to invert InSAR data for subsurface source model parameters, accurate forward models must be produced. The standard procedure is to model the surface deformation by computing a matrix of analytic solutions (one for each pixel) for a dislocation in an elastic half space [Okada, 1986]. Since all surface deformations are produced by a subsurface change in volume, shape, or orientation, an approximate model can be constructed by imposing one or more dislocations in an homogeneous elastic half-space. For example, a surface subsidence signal from fluid withdrawl associated with production of an oil field can be modeled as a deflating point source (representing a decrease in fluid volume) in an elastic half-space. Or, the deformation pattern associated with fault rupture from an earthquake can be modeled as a dislocation of a fault plane in an elastic half-space. The advantage of using a dislocation model is that the solution is analytic (exact) rather than numeric (approximate) and is consequently much less computationally expensive. Analytic models can be computed in seconds rather than minutes or hours for the same or similar solution computed numerically. For each of the three areas of focus for this project: Seismic Hazards Mitigation, GNEM/NAI, and Energy Exploitation applications, we used the analytic dislocation model approach to construct an approximate starting model. These models were refined by minimizing the residuals between the predicted (model) and actual (InSAR data) surface deformations.

While elastic dislocation models are fast and relatively easy to construct, they do not include the dynamics or forcing functions (physics) associated with the actual sources. As a result, no timedependent behavior can be modeled and other types of constraints (e.g., temperature, pressure, density, permeability, porosity, etc.) cannot be incorporated into the models. To include these types of parameters and their time-dependent functions, finite element modeling (FEM) was used.

\section{Forward Modeling-Numeric (Finite Element) Modeling}

A small portion of funds from this project were used to purchase a government/research institution copy of a leading commercial FEM software package called "MARC/MENTAT" by MSC Software Corporation. Two members of our team completed 1 week of offsite training on the use and applications of this software. After becoming adequately proficient in using this software, we built a time-dependent FEM model of the same cluster of five past underground nuclear tests we modeled elastically (described above and in the aforementioned journal article). This model included the effects of gravity acting on a more realistic layered earth model, as well as the time-dependent relaxation that gives rise to the observed subsidence signal. Using our InSAR results as a constraint to the allowed surface deformation and deformation rate, we were able to determine realistic values for the predicted stresses and mechanical properties of the test site area. The results of this FEM modeling will be included in a future journal article when additional funding make it possible to complete this part of the study. We were only able to complete a viscoelastic representation of the time-dependent subsidence signal. The next step was to incorporate a "Coulomb Failure" model where we impose a set of failure criterion on pre-existing underground cracks representing the damage zone above the emplacement cavities of the five underground nuclear tests. This would be a more accurate representation of the actual source of the observed subsidence signals. Unfortunately, the project ended before we could finish this model. 


\section{Inverse Techniques}

Although forward modeling can produce accurate models, they require considerable time and expertise (gained mainly by trial and error) to construct and refine. In addition, there is no statistical measure or "proof" that a particular forward model is in fact the best fit to the data. To greatly reduce the effort and time required, and to produce a statistically verifiable best-fit model to the data given the constraints (InSAR data with associated error estimates) an inversion technique is used. Using the elastic half-space forward model calculations for speed and tractability, an inversion code was developed to invert InSAR data for source parameters of interest. For example, we inverted an InSAR signal associated with subsidence from a cluster of five past underground nuclear tests in the Pahute Mesa subregion of the Nevada Test Site (NTS)-see section VII. The best-fit model using our new inversion tool was superior to our best-fit model from forward modeling only; and the solution was calculated in minutes rather than several hours for the forward modeling "by hand" approach.

In order to couple this new inversion tool to the more accurate FEM models, high performance computing is required since each FEM model calculation takes several minutes to run (on a typical workstation) and the inversion routine requires several thousand iterations (model calculations) to converge to a final best-fit solution. It is hoped that this coupling between FEM forward models and our inversion code can be the basis of a future project that utilizes LLNL's high performance computing capability.

\section{VII.Seismic Hazards Mitigation}

Using InSAR data, we discovered aseismic (no seismic waves or earthquake generated) slip events along the southern San Andreas fault system in Southern California. The equivalent seismic energy release expected from the fault offsets measured using InSAR would have produced magnitude 5.3 and 5.6 earthquakes (see attached paper: "Aseismic slip events along the southern San Adreas fault system captured by radar interferometry"). This discovery has important implications for seismic hazard mitigation as explained in the paper. Much of this work, as well as preliminary InSAR results for the San Francisco Bay region faults, was carried forth and continued from the Principal Investigator's Ph.D. Dissertation [Vincent, 1998].

\section{Ground-based Nuclear Explosion Monitoring (GNEM)}

The major area of focus of this project was on NAI applications relating to the GNEM (formerly CTBT) Program. The majority of publishable results can be found in the attached paper entitled "New signatures of underground nuclear tests revealed by radar interferometry". Other work in progress includes InSAR signals detected over mining operations in southwest Wyoming. These data include two mine collapses, which generated magnitude 5.3 and 4.7 seismic events respectively in 1995 and 2000 . We are using these InSAR signals to help us develop a way to discriminate between mine collapses and underground explosions, which look similar in seismic recordings and can be mistaken for one another.

\section{Energy Exploitation Applications}

Due to limitations in resources, this category received the least amount of effort among the three. However, the tools developed and applied to the other two areas of focus can easily be applied to energy exploitation-related applications. The work completed consists of InSAR data purchased and processed to image the Dixie Valley geothermal field (one of our study areas). Clear InSAR signals are visible over producing geothermal wells and we have identified both a deep and a shallow source depth for the observed displacement gradients. The displacement gradients correspond to mapped subsurface pressure gradients obtained from shallow geophysical measurements taken by researchers at the Energy \& Geoscience Institute, University of Utah. This preliminary work will be completed in a future Geothermal Programs Office, DOE project. 


\section{Future Work}

Future work includes improving and updating our InSAR processing ability to include the next generation of commercial SAR satellites scheduled for launch in ' 02 and ' 03 . In addition, work needs to be done to incorporate other types of remote sensing imagery and data for additional information and added constraints to our models. Continuation of our FEM modeling, and the development of an inversion tool that utilizes the FEM models, we anticipate will be part of a future project. 